\title{
Influences of high temperature on mechanical properties of fly ash based geopolymer mortars reinforced with PVA fiber
}

\author{
Mehmet Kaya (Main and Corresponding Author) \\ Department of Civil Engineering, Yozgat Bozok University \\ Yozgat, 66900 (Turkey) \\ mehmet.kaya@bozok.edu.tr \\ https://orcid.org/0000-0002-8116-0123 \\ Fuat Köksal \\ Department of Civil Engineering, Yozgat Bozok University \\ Yozgat, 66900 (Turkey) \\ fuat.koksal@bozok.edu.tr \\ https://orcid.org/0000-0002-3436-1694 \\ Manuscript Code: 32799 \\ Date of Acceptance/Reception: 13.08.2021/24.04.2021 \\ DOI: 10.7764/RDLC.20.2.393
}

\begin{abstract}
In this study, a geopolymer composite containing PVA fiber was produced to recycle waste fly ash and obtain an eco-friendly binder. Mechanical properties of geopolymer mortars, produced by using $\mathrm{F}$ class fly ash which was activated with $\mathrm{NaOH}$ (sodium hydroxide), and reinforced by PVA (polyvinyl alcohol) fiber were investigated after high temperature effect. Geopolymer mortar samples produced by mixing with fly ash, sand, water and $\mathrm{NaOH}$ were placed in standard molds of $40 \times 40 \times 160 \mathrm{~mm}^{3}$. PVA fibers were used at percentages of $0.5 \%, 1 \%$ and $1.5 \%$ by volume in the experiment. Tests were performed on mortars exposed to high temperatures of $200^{\circ} \mathrm{C}, 400^{\circ} \mathrm{C}, 600^{\circ} \mathrm{C}$ and $800^{\circ} \mathrm{C}$ for physical and mechanical properties. For the specimens not subjected to high temperatures, an increase in the compressive strength of mortars containing PVA fibers was observed in comparison to mortar without PVA fiber. On the other hand, it was concluded that losses in compressive strength were less for mortar without PVA fiber when compared with the mortars containing PVA fibers. As a result of the modeling, the PVA ratio, which gives the optimum flexural and compressive strength, was determined as $1.47 \%$. As a result of melting of PVA fibers under the effect of high temperature, $83.58 \%$ loss of compressive strength was determined in samples containing $1.5 \% \mathrm{PVA}$ after $800^{\circ} \mathrm{C}$ temperature.
\end{abstract}

Keywords: geopolymer, fly ash, polyvinyl alcohol, high temperature, flexural strength, compressive strength.

Introduction

Greenhouse gases are one of the most important problems today. Greenhouse gases, especially $\mathrm{CO}_{2}$, cause global warming and threaten human health. As of 2017, the world's $\mathrm{CO}_{2}$ emissions reached 36.5 billion tons annually (Ritchie et al. 2021). It has been stated that 2018 cement production in the world has reached 4.1 billion tons, and 1.5 billion tons of the total $\mathrm{CO}_{2}$ emission were caused by the cement sector (Global Carbon Atlas, 2020; Applications, Science, 2020). In addition, the use of fossil fuels to meet energy needs also causes $\mathrm{CO}_{2}$ emissions. As of $2018, \mathrm{CO}_{2}$ emissions of coal-based fuels reached 14.6 billion tons (Applications, Science, 2020) Fly ash released during the combustion of coal threatens human health. The storage is a problem in terms of sustainable environmental protection. Due to the environmental problems of the cement sector, efforts are continuing to produce an alternative binder to cement. Industrial wastes such as blast furnace slag, fly ash, floor ash and silica fume are activated with various alkalis (Bingöl et al. 2020; Şahin, Mahyar \& Erdoğan 2016). As a result of this chemical activation, cement-like binder can be produced. Materials such as lime, metakaolin (Bernal et al., 2010), red mud (Muraleedharan \&Nadir 2021), andesite dust (Çelikten, 2021) can also react with alkalis and gain binding properties. The binder formed with these alkaline activated materials is called geopolymer (Davidovits, 1989).

Geopolymer concretes produced by activation of alkalis have high flexural and compressive strength (Atiş et al., 2015; Kaya et al., 2020; Ling, Zhang, et al., 2019; Neupane, 2018). Activator ratio (Shi et al., 2018; Wang et al., 2020), aggregate properties (Abdullah et al., 2015; Keke et al., 2019), water/binder ratio (Aydın,2010), curing time and curing temperature (Durak et al., 2021), binding properties (Kaya et al., 2020) are the factors affecting the mechanical strengths of geopolymers. The $\mathrm{SiO}_{2} / \mathrm{Na}_{2} \mathrm{O}$ ratio, defined as the silicate modulus of the activator, is also effective on strength (Aydın, 2010; Bernal et al., 2010). High temperature is required for rapid reaction in geopolymer concretes produced with binders such as blast furnace slag and fly ash (Durak et al., 2021; Kaya et al., 2020). The most common known activators are sodium hydroxide (Durak et al., 2021; Rifaai et al., 2019) potassium hydroxide (Okoye, Durgaprasad \& Singh 2015; Rahmiati et al., 2014) sodium silicate (Atabey et al., 2020), and so on. In many studies, activation is achieved by mixing $\mathrm{NaOH}$ and sodium silicate in different ratios (Atabey et al., 2020; Balcikanli \& Ozbay 2016; Ugur Durak et al., 2021; Kaya 
et al., 2020). The reaction called geoplomerization is complex and has not been fully understood to date. In addition, the reaction has been reported to consist of steps such as dissolution of alumino silicate solids, gel formation, polycondensation and geopolymer formation (Zhang et al., 2016).

Geopolymer concrete has positive properties such as high mechanical strength (Atiş et al., 2015; Kaya et al., 2020; Ling, Wang, et al., 2019; Neupane, 2018), high abrasion resistance (Atabey et al., 2020; Atiş et al., 2015), high temperature resistance, low shrinkage (Çelikten, Sarıdemir, \& Özgür Deneme 2019; Kaya et al., 2018), high freeze-thaw resistance (Atabey et al., 2020; Atiş et al., 2015; Aygörmez, 2021). However, it has insufficient properties such as low sulfate resistance (Aydın, 2010; Elyamany, Abd Elmoaty \& Elshaboury, 2018). In a study in which lightweight alkali activated concrete was produced with basaltic pumice, fly ash and blast furnace slag, it was stated that the samples showed very good durability against acid attacks compared to the control samples with portland cement (Sarıdemir \& Çelikten 2020).The development of geopolymer concrete has increased rapidly over the last decade (Diaz-Loya, Allouche \& Vaidya 2011; Ryu et al., 2013; Sofi et al., 2007). Alomayri (2019) reported that the flexural strength, flexural modulus, fracture toughness, compressive strength and impact strength increased in the geopolymer paste produced by using fly ash with Nano- $\mathrm{Al}_{2} \mathrm{O}_{3}$ added at different ratios. Kaur et al. (2018) activated mixtures with 0 to $10 \%$ nano-metakaolin substitutes in replacement of fly ash with $\mathrm{NaOH}$. They also stated that an increase in compressive strength of the geopolymer mortars containing 4\% nano-metakaolin was observed. Ravitheja \& Kumar (2019), observed that compressive strength was improved in geopolymers, containing fly ash, produced by nano clay.

Polyvinyl alcohol (PVA) was first produced in 1924 (Jones, 1973). PVA is a material used in many industries such as textile, paint, medicine, food. It is also used as a binder and catalytic agent in the construction sector, and as a fiber in the cementitious composite (DeMerlis \& Schoneker 2003; Xu et al., 2018) In recent years, there have been studies on treated cementitious composites. PVA fibers are reported to increase compressive strength in the geopolymer matrix (Xu et al., 2018). PVA fiber has some advantages such as increased energy absorption and toughness in the matrix, increased strength and increased ductility (Arısoy, 2002). Tanyildizi \& Yonar (2016) tested geopolymer concretes, containing different amounts of PVA fiber, exposed high temperatures of $200^{\circ} \mathrm{C}-800^{\circ} \mathrm{C}$. They found that the flexural and compressive strengths of the geopolymers increased with increasing fiber content in the mixture. However, it is also reported that flexural and compressive strengths of samples exposed to high temperature decreased. In another study, it was stated that flexural and compressive strengths of geopolymers containing fly ash were improved by addition 6\% nano-silica to the mixture (Arısoy, 2002). A similar result for flexural strength was obtained by Ling et al. and they also reported that nano-silica adversely affected workability of geopolymer (Ling, Zhang, et al., 2019). (Xu et al., 2017) reported that PVA fibers increased flexural toughness of fly ash geopolymer composites.

The study presented here concerns the investigation of the effect of PVA fibers on physical and mechanical properties of geopolymer mortars containing fly ash under high temperatures. The optimum PVA ratio was determined as a result of the modeling made according to the results obtained from the high temperature experiment.

Methodology

\section{Materials}

Class F fly ash was obtained from by Turkey's Sugözü Thermal Power Plant. The maximum particle size of fly ash is 75 $\mu \mathrm{m}$, and its experimentally obtained physical and chemical properties are given in Table 1. XRD (X-ray diffractometer) results of class F fly ash and SEM (scanning electron microscope) images are given in Figure 1 . The PVA used in the study is shown in Figure 2. The properties of the PVA is also given in Table 2. Fine sand of limestone origin with a specific gravity of 2.63 and a water absorption capacity of $0.98 \%$ was used in the production of mortar. F class fly ash was activated with $\mathrm{NaOH}$ to produce geopolymer mortar samples. The binder/sand ratio was $1 / 3$ and the water/binder ratio was 0.30 . All of the geopolymer mortars with and without PVA fiber were prepared by mixing $14 \%$ by weight Na (sodium), fly ash and sand with water. Mixing was carried out in a standard cement mixer. The ratios of PVA fibers in fiber mortar specimens were planned as $0.5 \%, 1 \%$ and $1.5 \%$ by volume. 
Table 1. Properties of fly ash. (Self-Elaboration).

\begin{tabular}{cc}
\hline Chemical properties & (\%) \\
\hline $\mathrm{MgO}$ & 1.65 \\
$\mathrm{Al}_{2} \mathrm{O}_{3}$ & 21.69 \\
$\mathrm{SiO}_{2}$ & 60.51 \\
$\mathrm{SO}_{3}$ & 0.53 \\
$\mathrm{Na}_{2} \mathrm{O}$ & 0.92 \\
$\mathrm{~K}_{2} \mathrm{O}$ & 2.58 \\
$\mathrm{CaO}$ & 1.52 \\
$\mathrm{Fe}_{2} \mathrm{O}_{3}$ & 7.85 \\
Free $\mathrm{CaO}(\%)$ & 0.18 \\
Ignation loss & 2.57 \\
\hline Physical properties & \\
\hline Specific weight $\left(\mathrm{t} / \mathrm{m}^{3}\right)$ & 2.65 \\
45 micron sieve remaining $(\%)$ & 8.8 \\
Blain specific surface $\left(\mathrm{cm}^{2} / \mathrm{g}\right)$ & 2360 \\
\hline
\end{tabular}

Figure 1. XRD analysis and SEM image of class F fly ash. (Self-Elaboration).

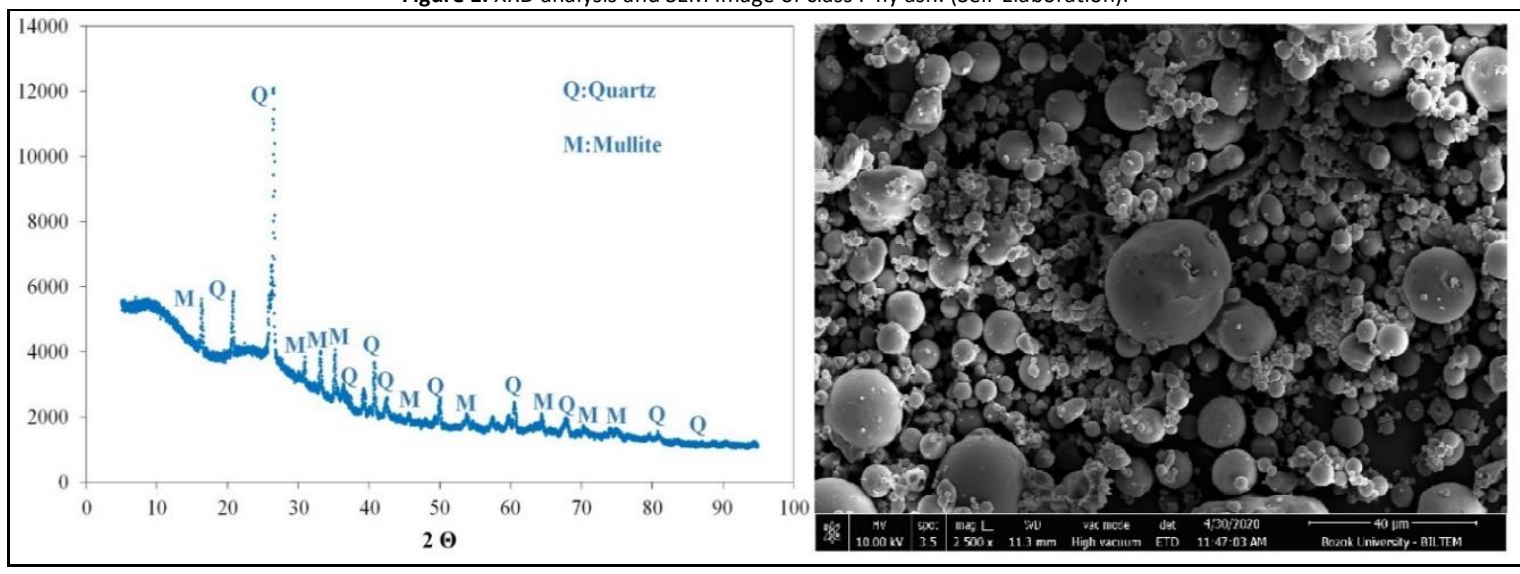

Table 2. Properties of PVA fiber. (Self-Elaboration)

\begin{tabular}{cccc}
\hline $\begin{array}{c}\text { Diameter } \\
\text { (micron) }\end{array}$ & $\begin{array}{c}\text { Length } \\
(\mathrm{mm})\end{array}$ & $\begin{array}{c}\text { Tensile strength } \\
(\mathrm{GPa})\end{array}$ & Elastic Modulus (GPa) \\
\hline 40 & 8 & 1,6 & 42 \\
\hline
\end{tabular}

Figure 2. PVA used in the study. (Self-Elaboration).

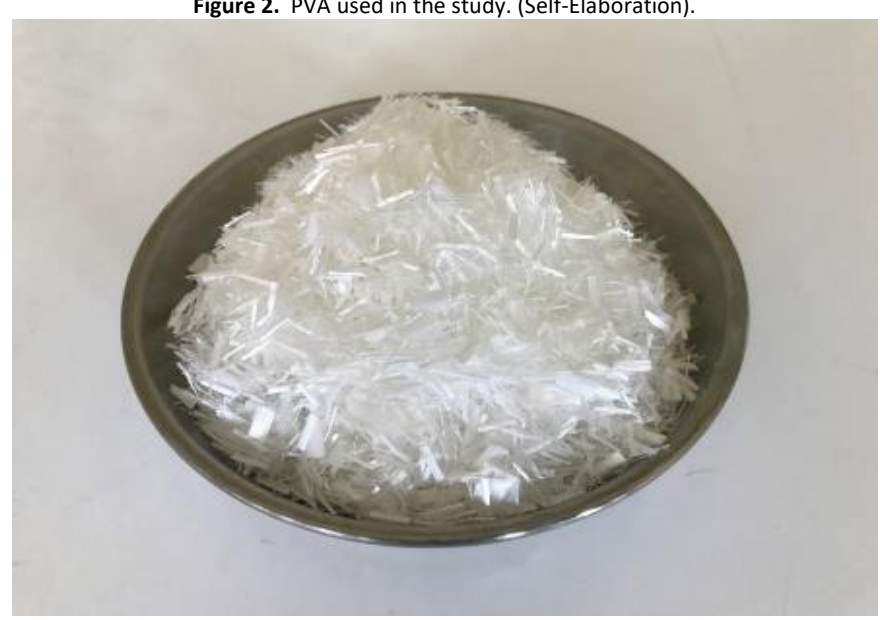


The geopolymer samples were placed in standard molds of dimensions $40 \times 40 \times 160 \mathrm{~mm}^{3}$. The mixing, molding, heating and curing steps of the mortar are shown in Figure 3. In some geopolymer studies containing fly ash, temperatures between $80^{\circ} \mathrm{C}$ and $100^{\circ} \mathrm{C}$ were used for high strength (Atabey et al., 2020; Atiş et al., 2015; Durak et al., 2021; Kaya et al., 2020). All samples were exposed to heat at $95^{\circ} \mathrm{C}$ for 24 hours. Heat cured samples were kept in the ambient temperature of laboratory $\left(\sim 23-25^{\circ} \mathrm{C}\right)$ up to 28 days.

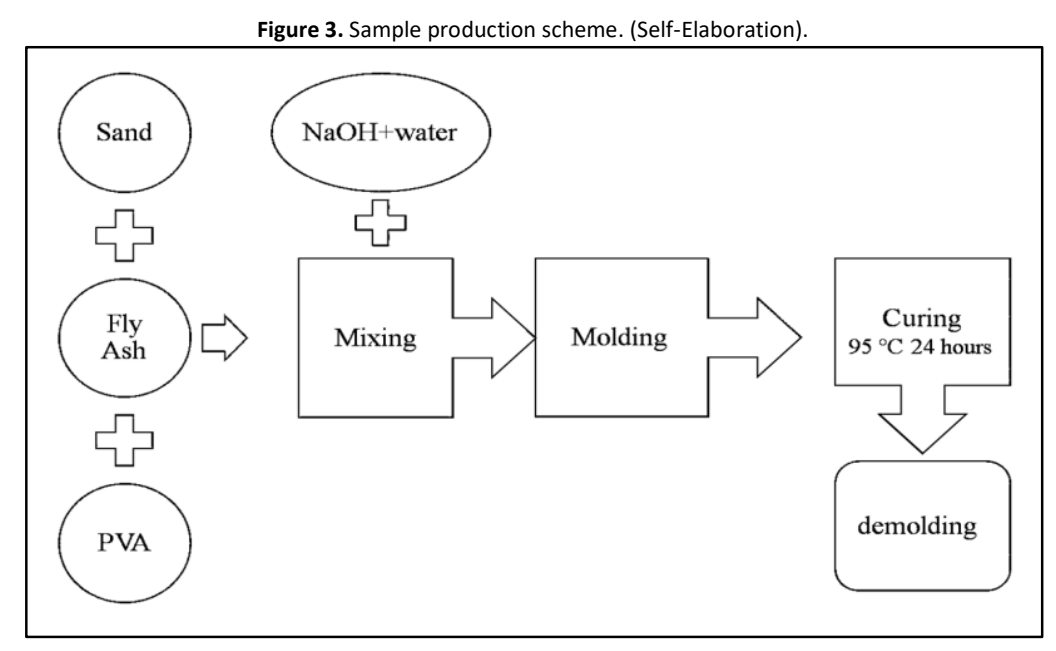

The mix proportions of the mortar samples are given in Table 3. For each testing temperature including ambient temperature, a total of twenty series mortar specimens were produced.

Table 3. Mix proportions of mortars. (Self-Elaboration).

\begin{tabular}{ccccc}
\hline Mix code & Fly ash/sand & Water/fly ash & Sodium/fly ash (\%) & PVA volumetric (\%) \\
\hline PVA0 & $1 / 3$ & 0.30 & 14 & 0 \\
PVA5 & $1 / 3$ & 0.30 & 14 & 0.5 \\
PVA10 & $1 / 3$ & 0.30 & 14 & 1.0 \\
PVA15 & $1 / 3$ & 0.30 & 14 & 1.5 \\
\hline
\end{tabular}

In the scope of experimental study, fresh mortar consistency (with flow table) was measured according to EN 1015-3 (TS EN 1015-3, 1999). Unit weight, water absorption, porosity and ultrasonic pulse velocity (UPV) tests were performed on the hardened mortar samples after the curing process was finished at the end of 28 days. Furthermore, flexural and compressive strength tests were carried out on prismatic samples of $40 \times 40 \times 160 \mathrm{~mm}^{3}$ dimensions with respect to EN 1015-11 (TS EN 1015-11, 2019) standard. After tests of control series specimens kept in ambient temperature were finished, other samples were subjected to high temperatures of $200^{\circ} \mathrm{C}, 400^{\circ} \mathrm{C}, 600^{\circ} \mathrm{C}$ and $800^{\circ} \mathrm{C}$. Samples in each temperature group were allowed to cool for 1 hour after reaching the target temperature, and then allowed to cool in room temperature. Flexural and compressive strength tests were also made on specimens after high temperature effect. After high temperature, weight losses and UPV of the samples were tested.

\section{Results and discussion}

As a result of the consistency test carried out on fresh mortar mixtures, it was determined that the flow table value of the samples without PVA fiber was higher than the samples containing PVA fiber. It means that the workability decreased with an increasing amount of PVA fiber in the mixture. With the increase of fiber amount, a decrease in flow table values was also observed. While the spread value was $132 \mathrm{~mm}$ in non-fiber geopolymer samples, $112 \mathrm{~mm}$ spread value was determined in samples containing 1.5\% PVA fiber. In geopolymer concretes containing PVA, it is stated that the workability decreases significantly with increasing amount of PVA (DeMerlis \& Schoneker, 2003). The flow table test results are shown graphically in Figure 4. 
Figure 4. Flow table test values of samples. (Self-Elaboration).

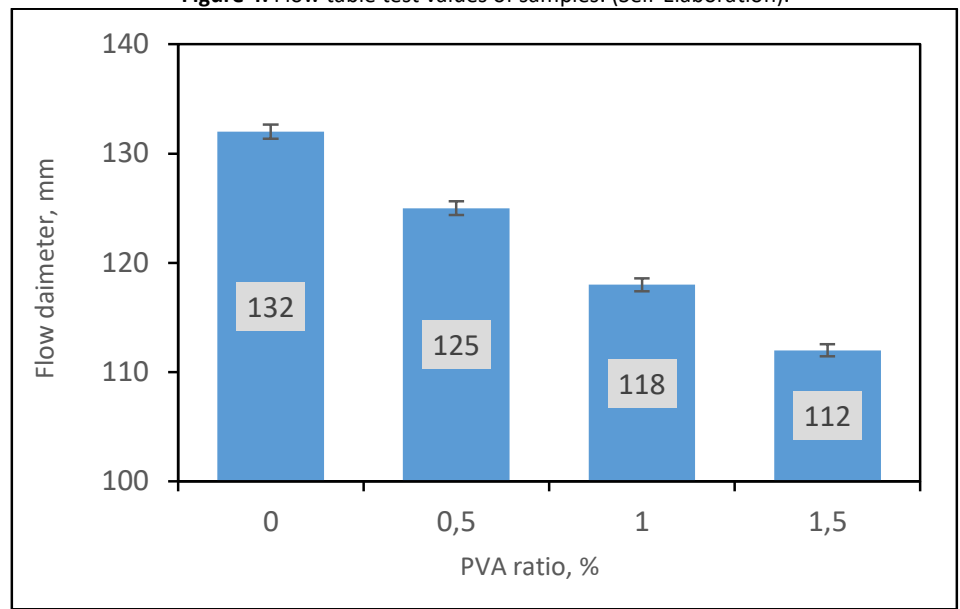

Dry unit weight, porosity, water absorption ratio, flexural and compressive tests were all done on hardened $40 \times 40 \times 160$ $\mathrm{mm}^{3}$ sized samples. Dry unit weights of samples vary between 20.4 and $22.1 \mathrm{kN} / \mathrm{m}^{3}$. It is observed that the unit weights decrease with the increase in the amount of PVA. Unit weights of the mortar samples are shown in Figure 5.

Figure 5. Dry Unit weight of samples. (Self-Elaboration).

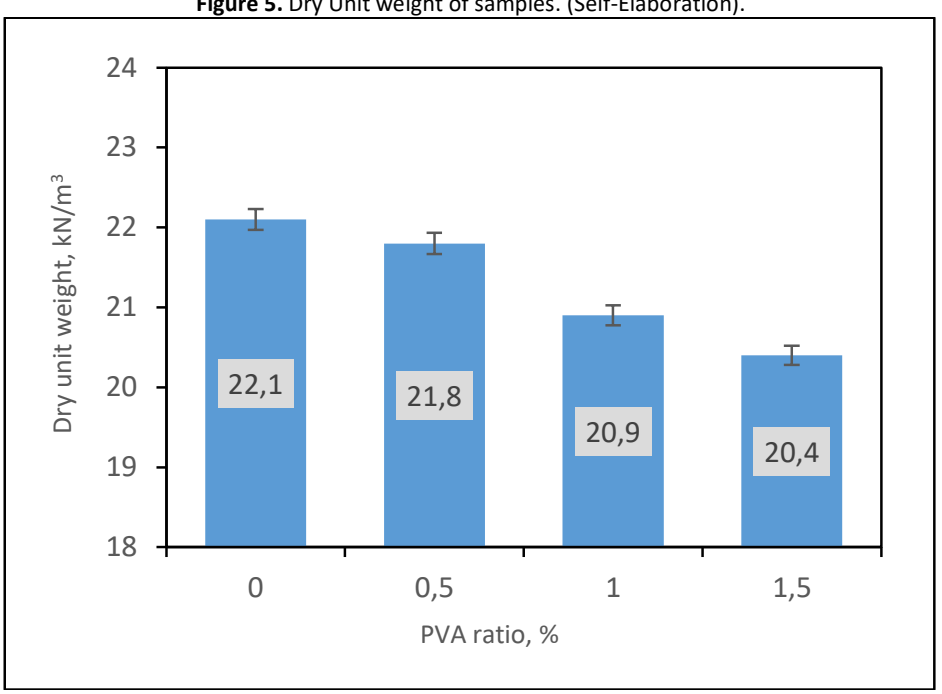

An increase in the amount of PVA fiber and an increase in water absorption ratios were observed. The lowest water absorption ratio was 2,4\% for samples without PVA fiber and the highest water absorption ratio was 7,5\% for samples containing 1,5\% PVA fiber. The water absorption ratios of the samples are given in Figure 6 . This increase in water absorption may be due to the voids result in clumping of PVA fibers during mixing and placing.

Figure 6. Water absorption ratio test results. (Self-Elaboration).

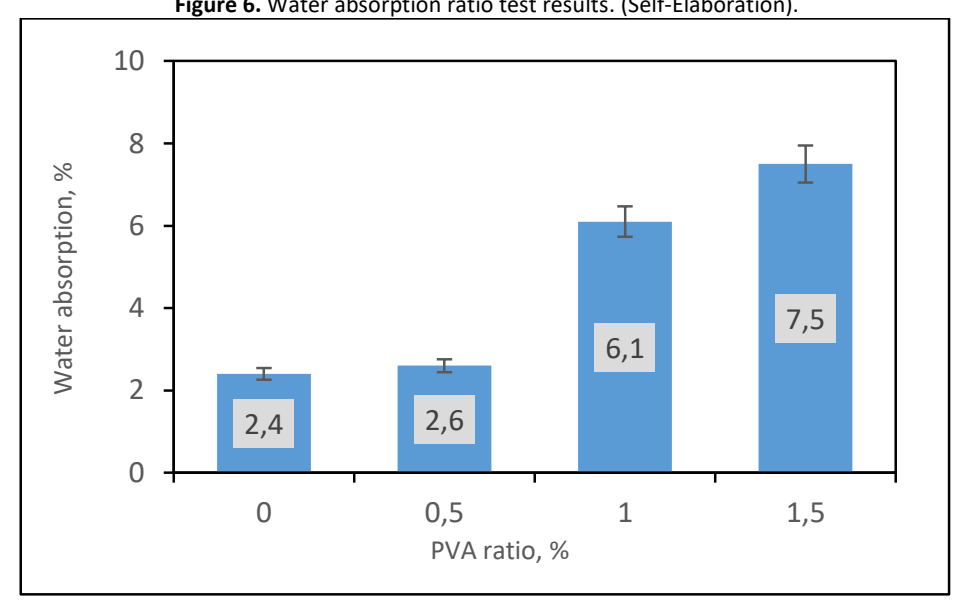


As the amount of PVA fiber increased, a certain increase in the porosity was observed. The porosity of samples without fiber was $5 \%$, while the porosity of samples containing $1.5 \%$ fiber was $13 \%$. The porosity test results are given in Figure 7. With the increase in the amount of PVA fiber in the mixture, the increase in water absorption ratio is similar to the literature (Xu et al., 2018). The porous structure of the geopolymer causes an increase in the amount of water absorption (Atabey et al., 2020; Kaya et al., 2018).

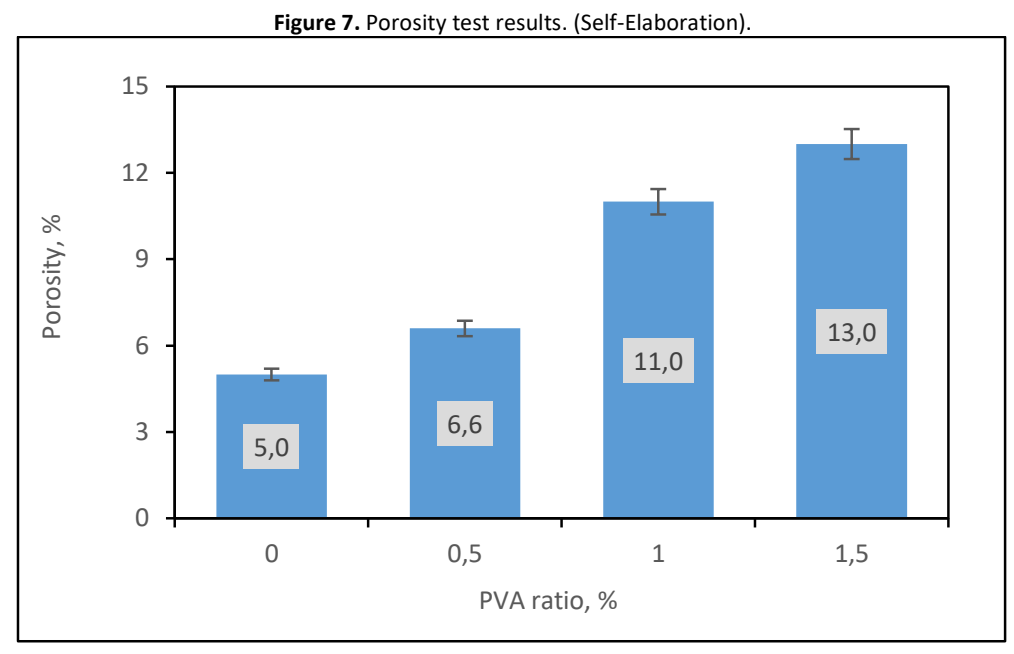

The UPV decreased with the increasing amount of PVA fiber. In fibreless samples, UPV was determined as $2.87 \mathrm{~km} / \mathrm{s}$. In samples containing $1.5 \%$ fiber, UPV was $2.53 \mathrm{~km} / \mathrm{s}$. The UPV of the samples is given in Figure 8 . As the ultrasonic will take time to pass through the void with the increasing void ratio, the UPV decreases. An increase in the cavity ratio and a decrease in UPV is an expected result.

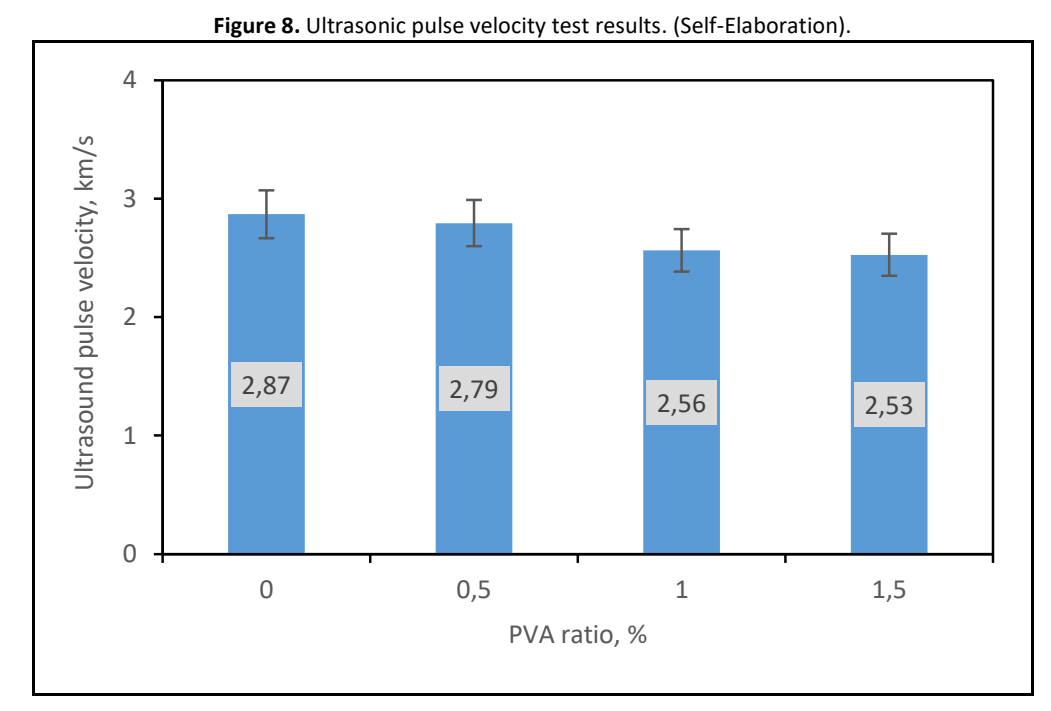

As the amount of PVA fiber increased, a certain increase was observed in flexural strength. Flexural strength of 12.66 MPa was observed in fiber free samples, while $13.02 \mathrm{MPa}$ flexural strength was determined in samples containing $1 \%$ fiber. The relation between flexural strength and high temperature is shown in Figure 9. In other studies, it has been found that flexural strength increases with the increase of PVA fibers in the geopolymer composite (DeMerlis \& Schoneker 2003; Tanyildizi \& Yonar 2016). In general, it is expected that all types of fibers used in mortars and concrete improve the flexural strength and toughness. As a result of the high temperature effect, flexural strength of all mixtures decreased. It was observed that the flexural strengths of PVA free samples were higher than PVA containing samples at all temperatures. Flexural strengths of PVA free samples ranged from $1.70 \mathrm{MPa}$ to $9.98 \mathrm{MPa}$. The flexural strength was determined as $7.37 \mathrm{MPa}$ after the temperature of $200^{\circ} \mathrm{C}$ and $1.02 \mathrm{MPa}$ after the temperature of $800^{\circ} \mathrm{C}$ in the samples containing 1.5\% PVA fiber. Ratio of reduction in flexural strength after high temperature in Figure 10. After high temperature PVA fiber free samples after $800^{\circ} \mathrm{C}$, flexural strength decreased by $86.57 \%$ and in $1 \%$ PVA fiber samples 90.86\%. The higher the PVA fiber content, the greater the loss of flexural strength as a result of high temperature was observed (Xu et al., 2018). 
Figure 9. Relations between flexural strength and high temperature. (Self-Elaboration).

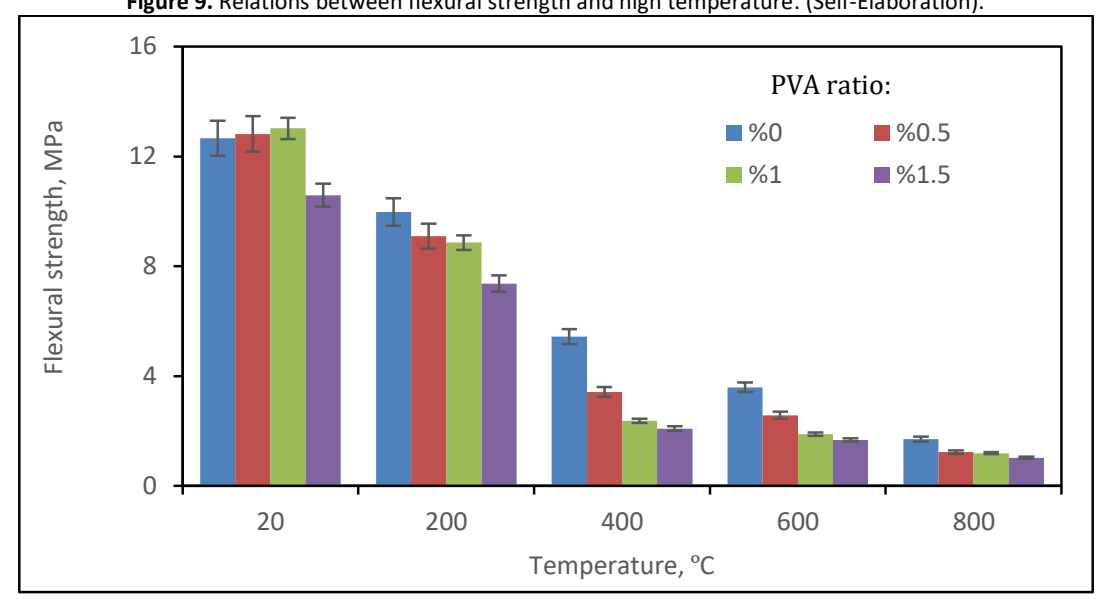

Figure 10. Ratio of reduction in flexural strength after high temperature. (Self-Elaboration)

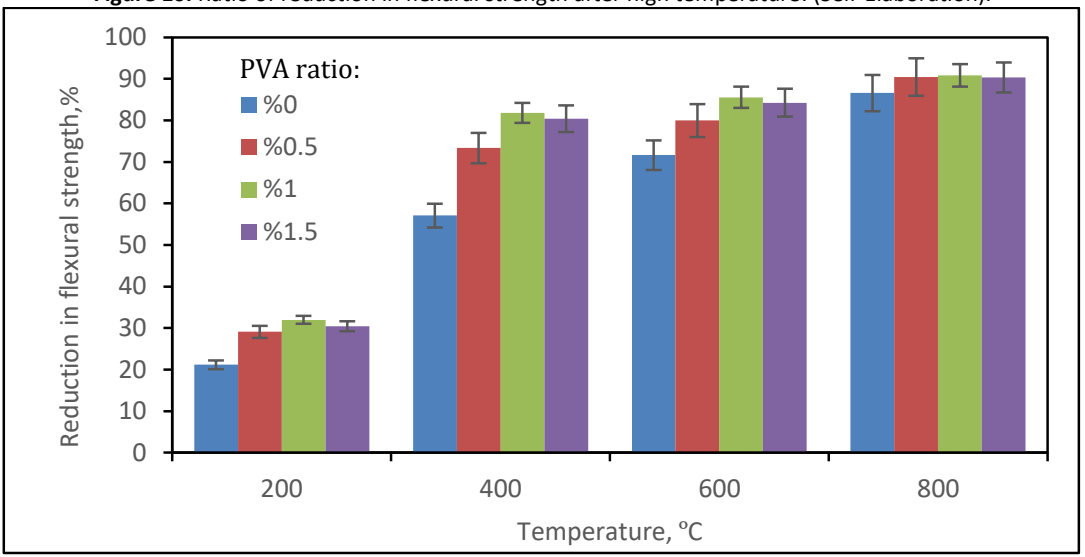

A certain increase in compressive strength was observed with the increasing amount of PVA fiber. Compressive strengths were obtained $40.73 \mathrm{MPa}$ in samples without PVA fiber and $51.95 \mathrm{MPa}$ in samples containing $1.5 \%$ PVA fiber, respectively. The compressive strength of the samples is shown graphically in Figure $11.8 .57 \%$ increase in compressive strength was observed in non-fiber samples after $200^{\circ} \mathrm{C}$ temperature. This is thought to be due to the non-activated activator in the sample. Some studies have shown an increase in compressive strength after high temperature effects in geopolymer mortars (Bernal et al., 2010; Kaya et al., 2018). After $800^{\circ} \mathrm{C}$, the loss of compressive strength of PVA free samples is $68.5 \%$. In the samples containing $0.5 \%, 1 \%$ and $1.5 \%$ PVA, the loss of compressive strength was $79.5 \%, 81.9 \%$, $83.58 \%$ in the samples. The increase in PVA fiber ratio caused a decrease in the strength after high temperature. It is thought that after high temperature PVA fiber melting increases the void structure and deterioration of the internal structure causes the strength decrease. It was observed that compressive resistance losses were less in all temperature groups of PVA free samples compared to PVA containing samples.

Figure 11. Relations between compressive strength and high temperature. (Self-Elaboration).

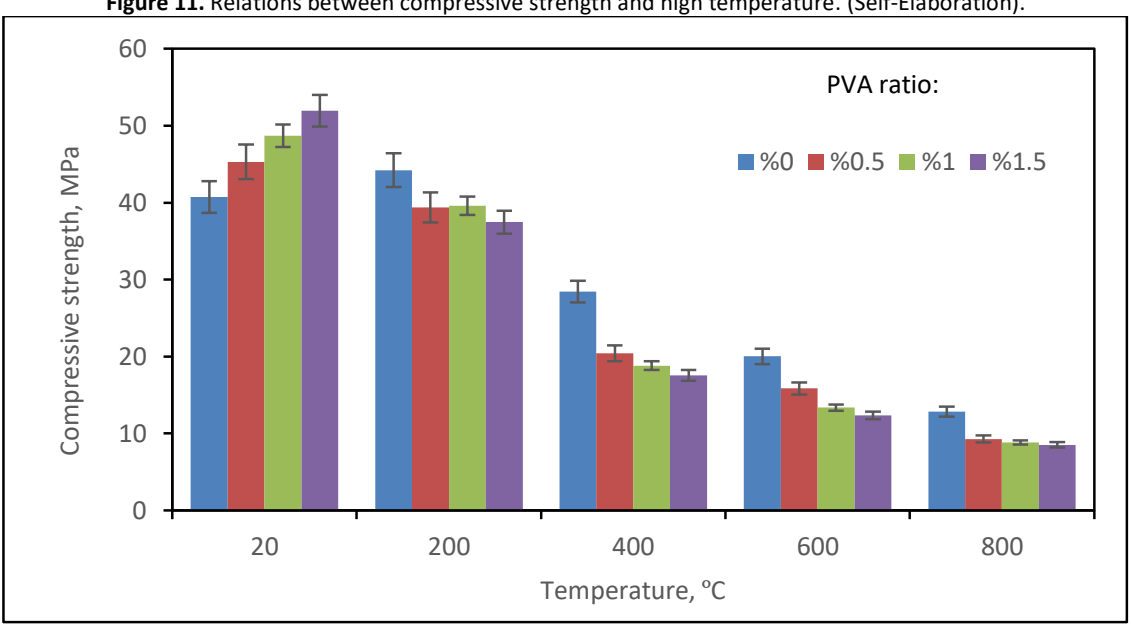




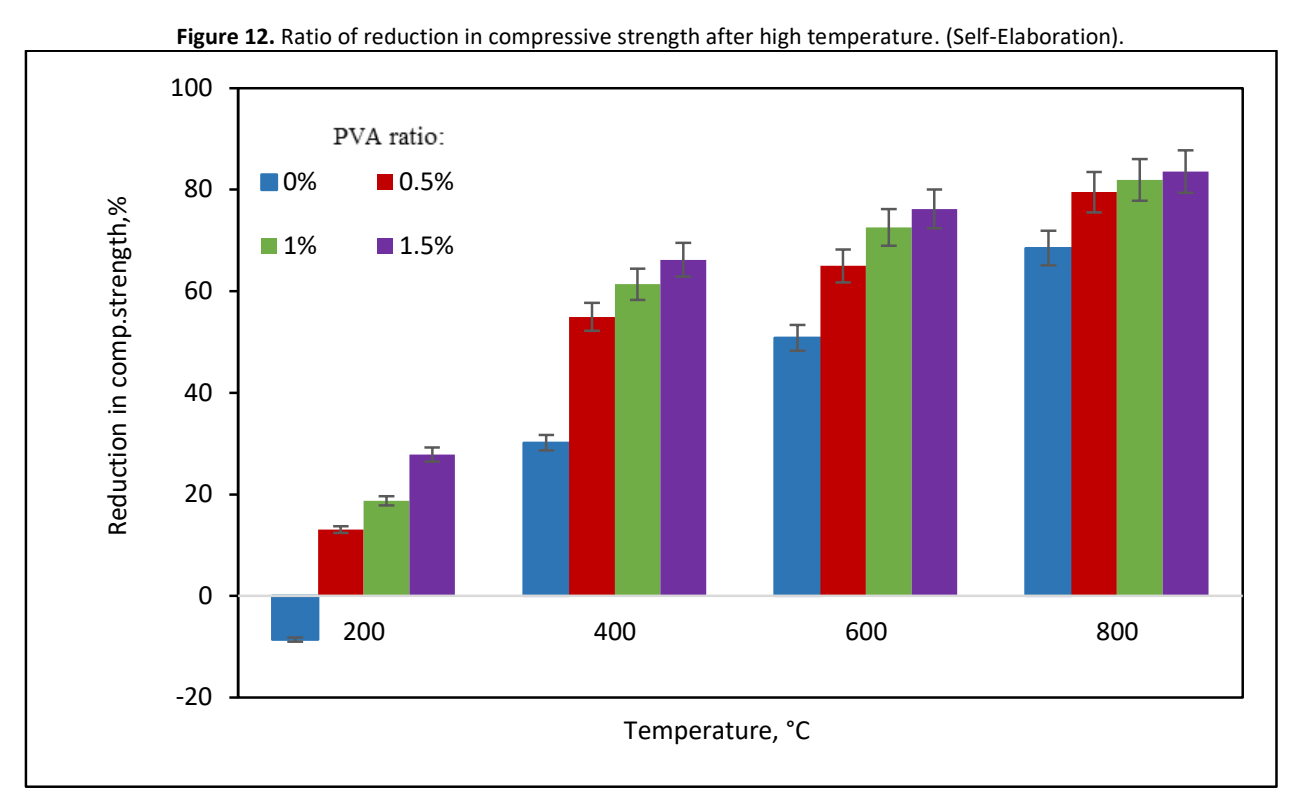

In the study performed by (Tanyildizi \& Yonar 2016) on geopolymer concretes containing PVA fiber, it is stated that the flexural and compressive strengths of the samples containing PVA fiber exposed to high temperature effect decreased. In the same study, it was reported that samples cured at $60^{\circ} \mathrm{C}$ showed better flexural and compressive strengths than samples cured at $80^{\circ} \mathrm{C}$ and $100^{\circ} \mathrm{C}$. Geopolymer samples produced by curing at low temperature around $50^{\circ} \mathrm{C}$ are known to have high temperature resistances compared to samples produced by curing at high temperature around $90^{\circ} \mathrm{C}$. They show good performance in low temperature cured samples in terms of high temperature resistance due to the presence of unactivated activator. Since they have activators in low temperature cured samples, they perform well in terms of high temperature resistance (Kaya et al., 2018). In this study, it is considered that geopolymer samples produced at $95^{\circ} \mathrm{C}$ have significant strength losses.

Reduction of UPV of samples after high temperature effect are given in Figure 13. With the effect of temperature, a decrease in UPVs of all samples was observed. In PVA free samples, a decrease of $10.77 \%$ UPV was observed at $200^{\circ} \mathrm{C}$, while samples containing $1.5 \%$ PVA decreased by $12.57 \%$. While the loss of UPV was $65.43 \%$ in samples PVA free samples at $800^{\circ} \mathrm{C}$ temperature, the loss of UPV in samples containing $1.5 \%$ PVA was determined as $66.22 \%$. A decrease in UPV was observed at all temperatures, with an increase in the amount of PVA in the samples. The increase in the void structure and the decrease of UPV due to post-temperature deterioration is similar to the literature (Kaya et al., 2020). The relationship between the flexural and compressive strengths of the samples is shown in Figure $14 . R^{2}=0.99$ shows a strong relationship between flexural and compressive strengths.

Figure 13. Reduction of UPV of samples after high temperature effect. (Self-Elaboration).

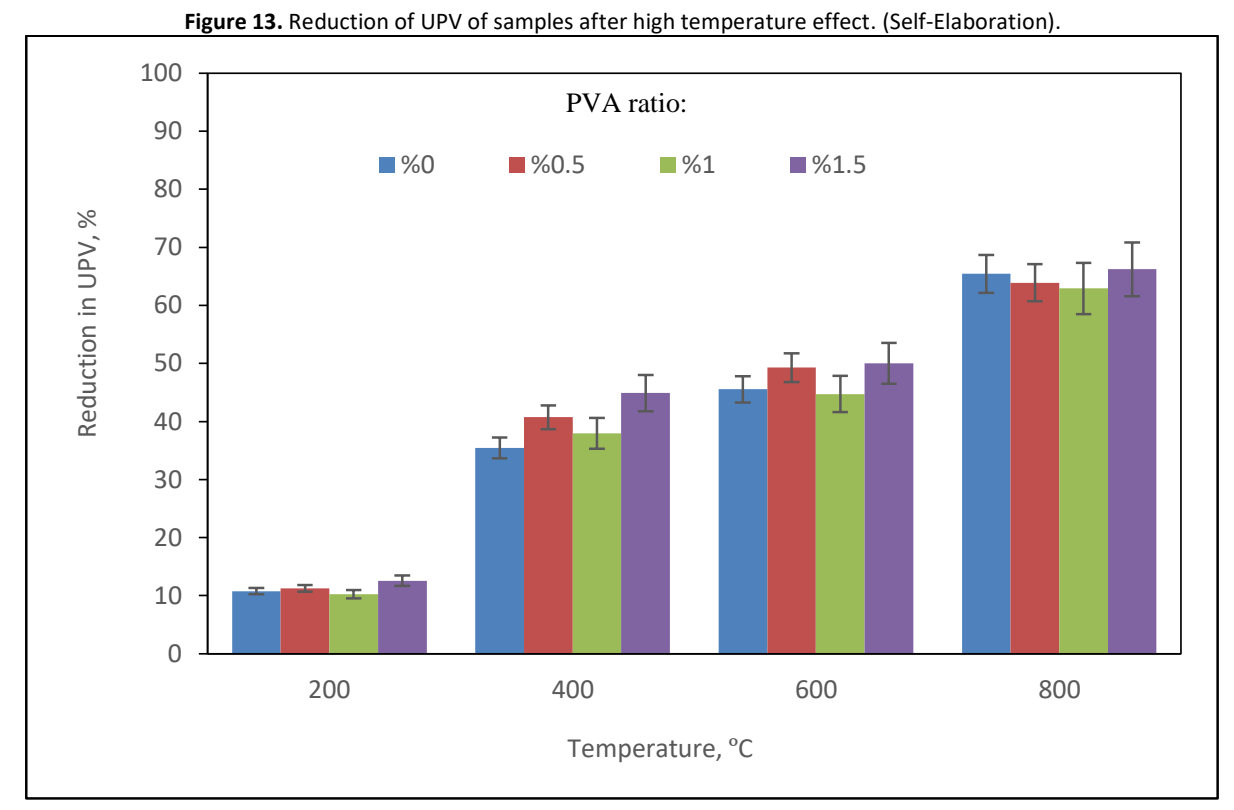


Figure 14. The relationship between the flexural and compressive strengths. (Self-Elaboration).

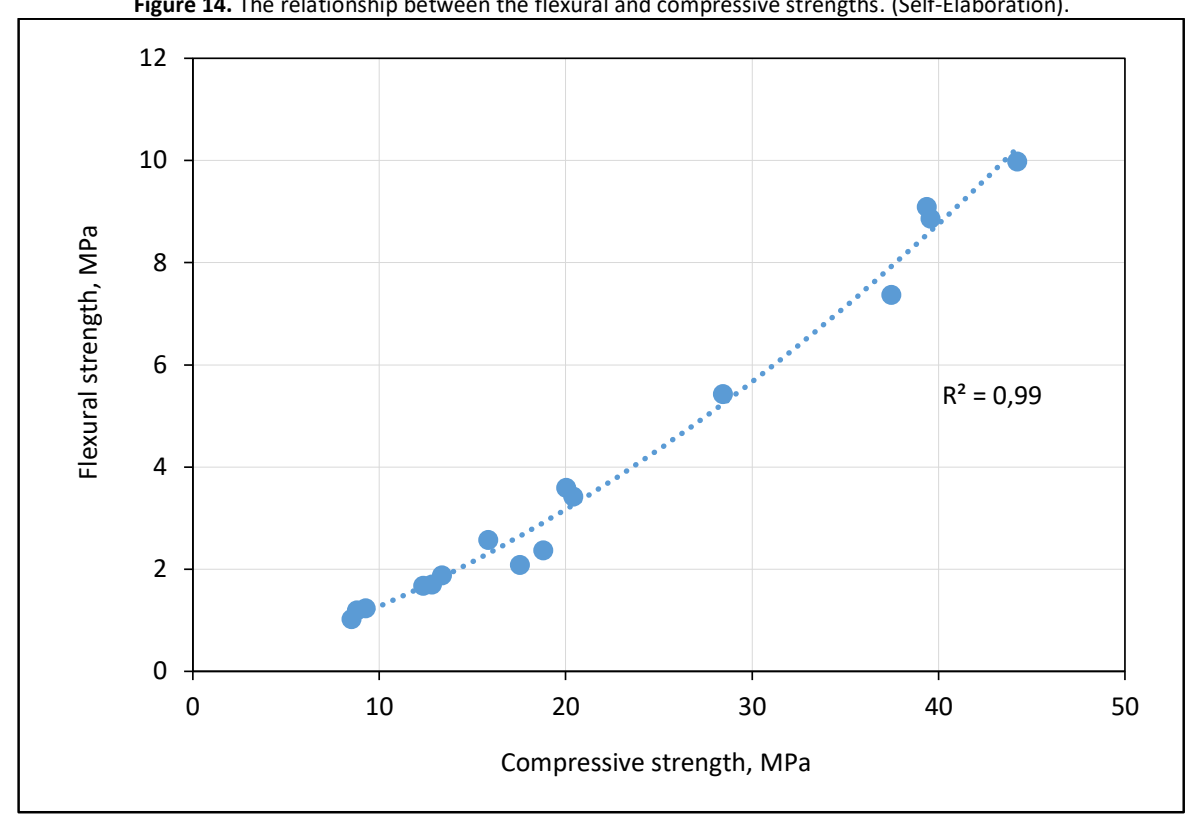

The relationship between the strengths of the samples before and after the high temperature with the ultrasonic pulse velocity ratio is shown in Figure 15. It is clearly seen that there is a strong relationship between flexural strength and UPV with the coefficient of determination of $R^{2}=0.97$. The relationship between compressive strength and UPV with the coefficient of determination of $R^{2}=0.96$. The relation shows that compressive strengths increase due to the increase in UPV ratio with the decrease of porosity.

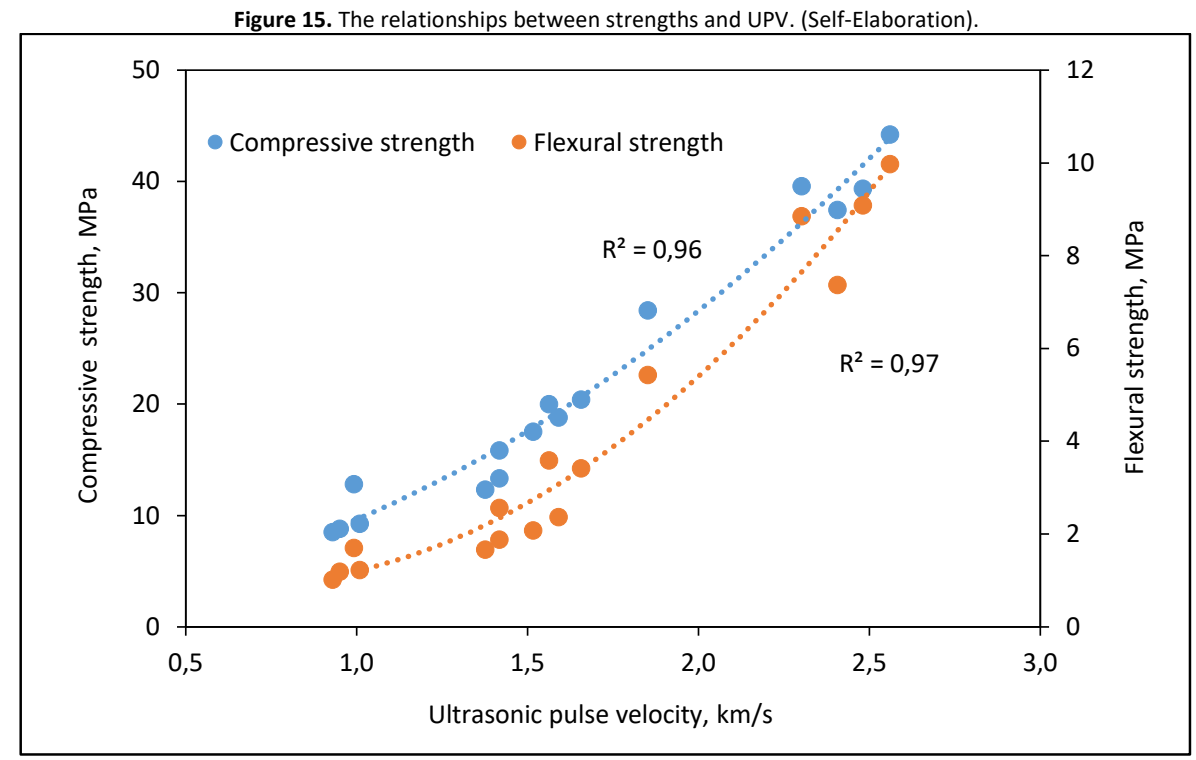

The SEM images of the geopolymer samples containing 1.5\% PVA before and after the temperature test are given in Fig. 16. In Fig. 16a, the image of the sample containing 1.5\% PVA fiber before applying the temperature is given. In Figures of $16 \mathrm{~b}$ and $16 \mathrm{c}$, SEM images are given after $400^{\circ} \mathrm{C}$ temperature. A SEM image of PVA fiber sample, after $600^{\circ} \mathrm{C}$ temperature, is shown in Fig. $16 \mathrm{~d}$. It was exposed to $400^{\circ} \mathrm{C}$ and $600^{\circ} \mathrm{C}$ temperature, and the samples could not be seen due to the melting of PVA fibers in the samples. It was observed that there was hole in the place where PVA fibers were located. In addition, ettringite formation was observed in the sample (Figure $16 \mathrm{c}$ ) exposed to $400^{\circ} \mathrm{C}$ temperature in the gap. In previous studies, it has been stated that in samples containing high-temperature fly ash, ettringite occurs with the effect of temperature (Chindaprasirt et al., 2013). 


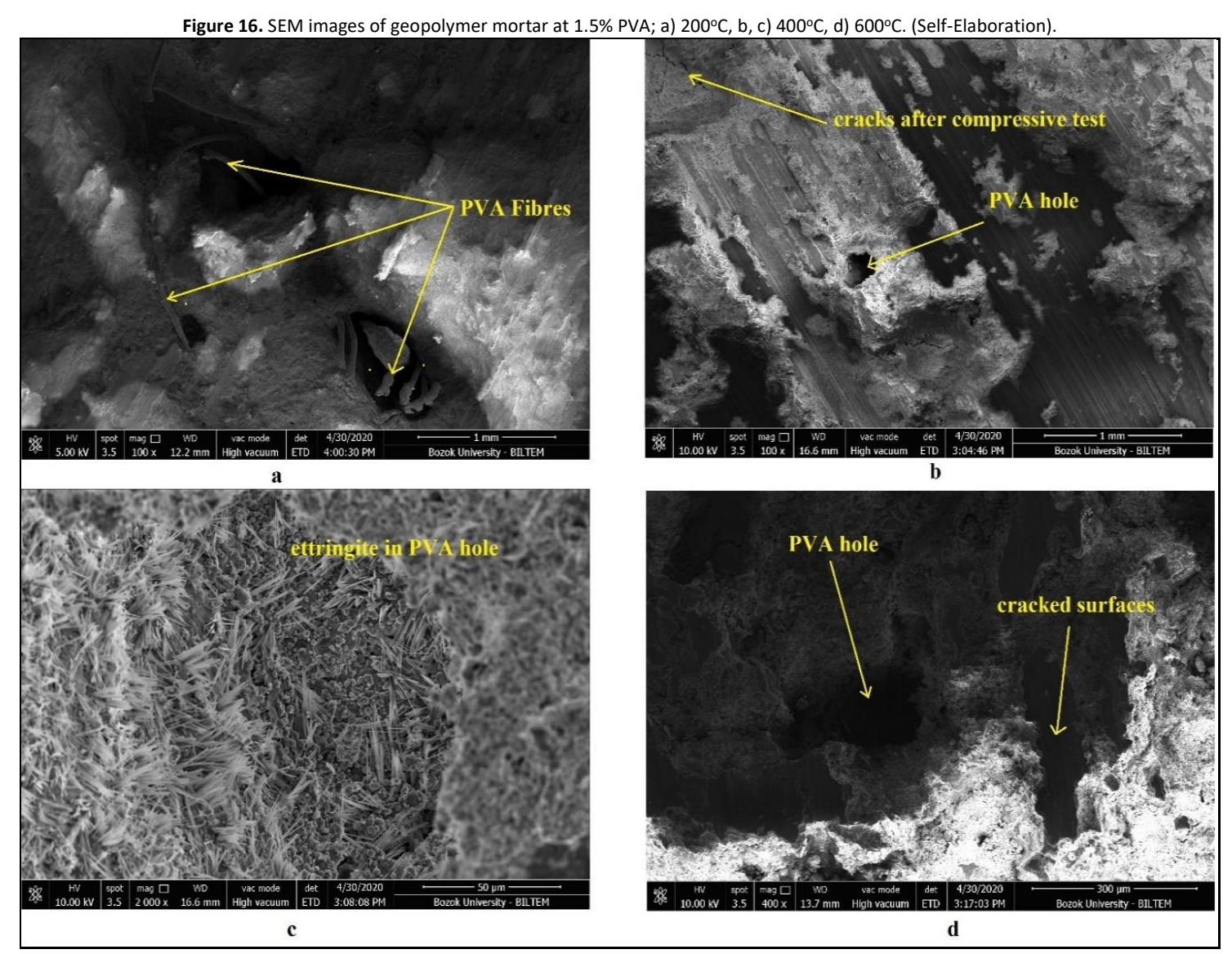

\section{Regression analysis of test results}

Regression analyses were made by using Response Surface Methodology (RSM) for flexural strength and compressive strength test data. The aim of regression analyses was to observe the changes in strengths (residual strengths) depending on PVA contents at elevated temperature effect.

RSM uses mathematical and statistical methods to establish a model by analyzing of a set of input (dependent variables) and output (independent variables or responses) data (Braima, Anozie, \& Odejobi, 2016) Models established for responses used to find optimum solutions for responses (Derringer \& Suich 1980; Montgomery, 2005). In this experimental design, independent variables were PVA ratios $(0 \%, 0.5 \%, 1 \%$ and $1.5 \%)$ and testing temperatures $\left(200^{\circ} \mathrm{C}\right.$, $400^{\circ} \mathrm{C}, 600^{\circ} \mathrm{C}$ and $800^{\circ} \mathrm{C}$ ). A total of $4 \times 4=16$ design points were used in establishing the models for responses (compressive and strength flexural strengths) PVA ratios and testing temperatures are coded as $P V A$ and $T$, respectively. $f_{c}$ and $f_{f}$ illustrate the compressive and strength flexural strengths, respectively.

A model for each strength was first established by using RSM incorporating best fitting surfaces depending on independent variables of PVA and T. To obtain the response surfaces, variance analysis (ANOVA) was performed by using design points. A 2 factor interaction (2FI) model for strength flexural strength and a quadratic model for compressive strength were used to obtain maximum $R^{2}$ (coefficient of determination) values.

Response surfaces of models, obtained for residual strengths of $f_{c}$ and $f_{f}$, were given in Fig. 18. Expressions of models are as follows:

$f_{f}=12.74-4.90 x(P V A)-0.016 x(T)+0.006 x(P V A) x(T)$

$f_{c}=68.06-9.59 x(P V A)-0.135 x(T)+0.0054 x(P V A) x(T)+0.534 x(P V A)^{2}$

The coefficients of determination $\left(R^{2}\right)$ of regression models, build for $f_{f}$ and $f_{c}$, were found as 0.83 and 0.97 . As a result of the answers received using independent variables ( $P V A$ and $T$ ), eq. (1) and eq. (2) were obtained. Figure 17. shows the residual strength values predicted by models and values obtained experimentally. The models, for prediction of residual strengths of PVA mortars, obtained by using test results of this experimental study have a good correlation 
between temperature and PVA content. Before the mix design of PVA mortars to be subjected to the elevated temperatures, the models can be usefull for estimation of residual strength depending on PVA content.

Figure 17. Response surfaces for residual flexural and compressive strengths. (Self-Elaboration).
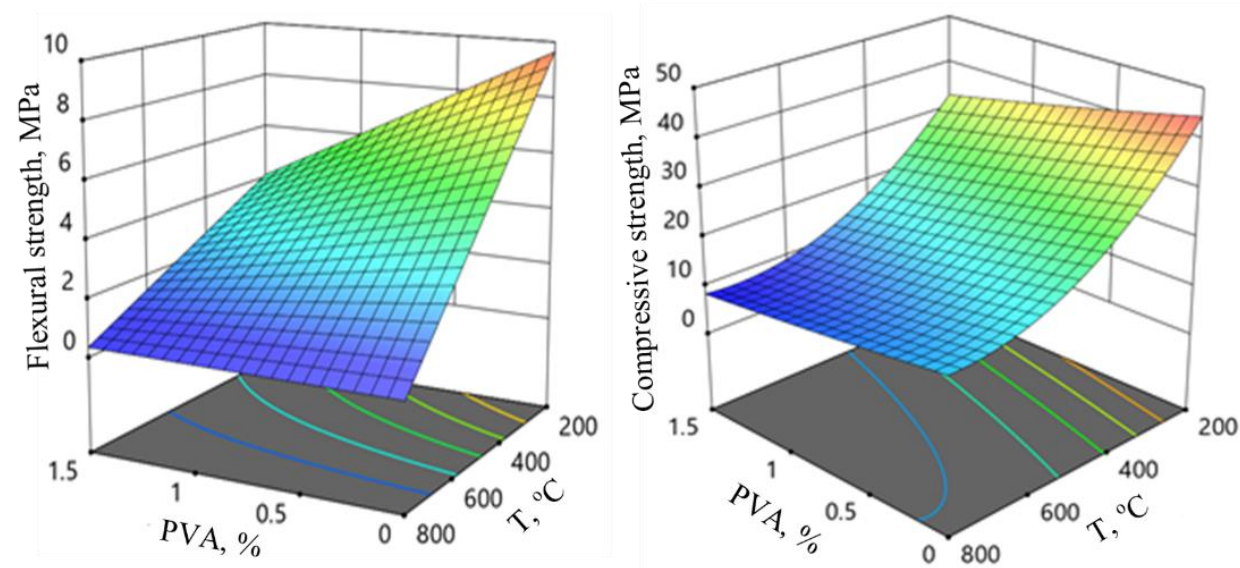

When the response surface for the compressive strength $\left(f_{c}\right)$ and flexural strength $\left(f_{f}\right)$ in Figure 17 is examined, It was observed that the compressive strength was high at low temperature values, and the compressive strength decreased with increasing temperature value. The compressive strength increases with the increase of PVA ratio at $200^{\circ} \mathrm{C}$. However, the compressive strength decreases between $600^{\circ} \mathrm{C}-700^{\circ} \mathrm{C}$. For $1.5 \% \mathrm{PVA}$, compressive strengths are $34 \mathrm{MPa}$ and $8.5 \mathrm{MPa}$ at $200^{\circ} \mathrm{C}$ and $800^{\circ} \mathrm{C}$, respectively. The highest flexural strength at PVA-free at $200^{\circ} \mathrm{C}$ was observed as 9.7 $\mathrm{MPa}$. However, the lowest flexural strength as $1,02 \mathrm{MPa}$ was obtained at the temperature range of $600^{\circ} \mathrm{C}-700^{\circ} \mathrm{C}$ at $1.5 \%$ PVA. Figure 18. shows the strength values predicted by models versus actual values.

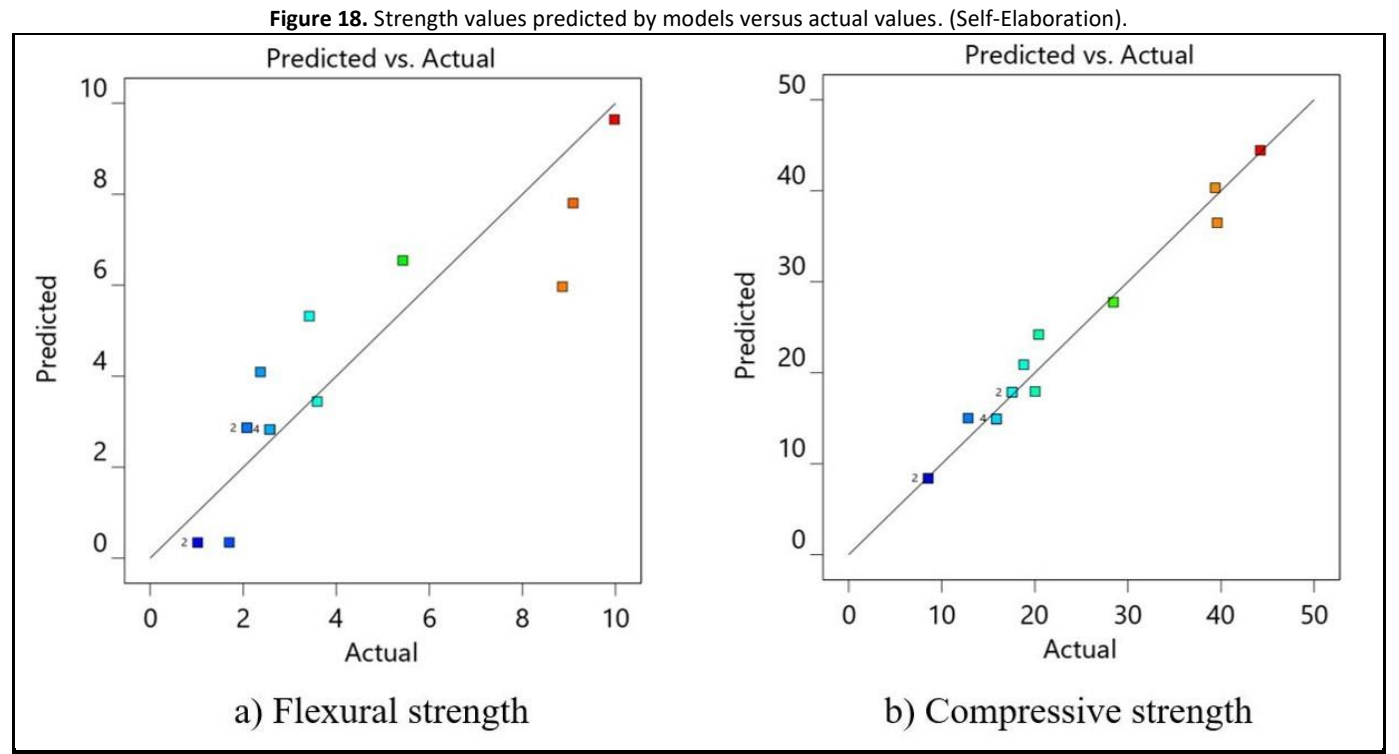

Conclusions

In this research, the effect of high temperature on mechanical properties in fly ash geopolymer mortars containing PVA fiber was investigated. The following results were obtained from the experimental studies:

- Flexural strengths of samples that do not contain PVA fiber after high temperatures showed the highest values. As PVA fiber ratio increased, it was observed that the loss of flexural strength as a result of high temperature was more. 
- The compressive strengths of the samples which do not contain PVA fiber at all temperatures showed the highest values. It was observed that compressive strength losses were less in all temperature groups of PVA free samples compared to PVA containing samples.

- PVA fiber additive has no positive contribution to flexural and compressive strengths after $200^{\circ} \mathrm{C}$. The reason of strength losses of fiber-containing samples can be explained by the degradation of PVA after $200^{\circ} \mathrm{C}$.

- Although it is known that geopolymer mortars perform well in terms of resistance to high temperatures (Kaya et al. 2018), the high loss of strength in this study is thought to be caused by the deterioration of limestone based aggregate after $600^{\circ} \mathrm{C}$ temperature.

- The models, for the prediction of residual strengths of PVA mortars, have a good correlation between temperature and PVA content. Before the mix design of PVA mortars to be subjected to the elevated temperatures, the models can be usefull for estimation of residual strength depending on PVA content.

- PVA fiber can be used when recycling fly ash in geopolymer production. PVA fibers contribute to the geopolymer strength at ambient temperature. However, no positive contribution to strength was observed under the high temperature effect.

Abdullah, Alida, Ku Amirrul Rahman Ku Yin, Mohd Mustafa Al Bakri Abdullah, Kamarudin Hussin, and Mien Van Tran. 2015. "Comparison of Mechanical Properties of Fly Ash Artificial Geopolymer Aggregates with Natural Aggregate." Applied Mechanics and Materials (Vol. 754, pp. 290-295). Trans Tech Publications Ltd. doi: 10.4028/www.scientific.net/amm.754-755.290.

Alomayri, Thamer. 2019. "Experimental Study of the Microstructural and Mechanical Properties of Geopolymer Paste with Nano Material (Al2O3)." Journal of Building Engineering 25, 100788. doi: 10.1016/j.jobe.2019.100788.

Applications, Science, and Sustainability of Coal Ash. 2020. https://www.acaa-usa.org, Accessed:12 Dec 2020

Arısoy B. 2002. "Development and Fracture Evaluation of High Performance Fiber Reinforced Lightweight Concrete.” Wayne State University

Atabey, İsmail İsa, Okan Karahan, Cahit Bilim, and Cengiz Duran Atiş. 2020. "The Influence of Activator Type and Quantity on the Transport Properties of Class F Fly Ash Geopolymer." Construction and Building Materials 264. doi: 10.1016/j.conbuildmat.2020.120268.

Atiş, C. D., E. B. Görür, O. Karahan, C. Bilim, S. Ilkentapar, and E. Luga. 2015. "Very High Strength (120 MPa) Class F Fly Ash Geopolymer Mortar Activated at Different $\mathrm{NaOH}$ Amount, Heat Curing Temperature and Heat Curing Duration." Construction and Building Materials 96, 673.678. doi: 10.1016/j.conbuildmat.2015.08.089.

Aydın S. 2010. "Development of a Fiber Reinforced Composite with Alkali Activated Ground Granulated Blast Furnace Slag." The Graduate School of Natural and Applied Sciences.

Aygörmez, Yurdakul. 2021. "Performance of Ambient and Freezing-Thawing Cured Metazeolite and Slag Based Geopolymer Composites against Elevated Temperatures." Revista de La Construcción 20(1). doi: 10.7764/RDLC.20.1.145.

Balcikanli, Müzeyyen, and Erdogan Ozbay. 2016. “Optimum Design of Alkali Activated Slag Concretes for the Low Oxygen/Chloride lon Permeability and Thermal Conductivity." Composites Part B: Engineering, 91, 243-256. doi: 10.1016/j.compositesb.2016.01.047.

Bernal, Susan A., Ruby Mejía de Gutierrez, John L. Provis, and Volker Rose. 2010. "Effect of Silicate Modulus and Metakaolin Incorporation on the Carbonation of Alkali Silicate-Activated Slags." Cement and Concrete Research, 4O(6), 898-907. doi: 10.1016/j.cemconres.2010.02.003.

Bingöl, Şinasi, Cahit Bilim, Cengiz Duran Atiş, Uğur Durak, Serhan Ilkentapar, and Okan Karahan. 2020. "An Investigation of Resistance of Sodium Meta Silicate Activated Slag Mortar to Acidic and Basic Mediums." Revista de La Construcción, 19(1), 127-133. doi: 10.7764/rdlc.19.1.127-133.

Çelikten, Serhat. 2021. "Mechanical and Microstructural Properties of Waste Andesite Dust-Based Geopolymer Mortars." Advanced Powder Technology 32(1), 1-9. doi: 10.1016/j.apt.2020.10.011.

Çelikten, Serhat, Mustafa Sarıdemir, and İbrahim Özgür Deneme. 2019. "Mechanical and Microstructural Properties of Alkali-Activated Slag and Slag + fly Ash Mortars Exposed to High Temperature." Construction and Building Materials, 217, 50-61. doi: 10.1016/j.conbuildmat.2019.05.055.

Chindaprasirt, Prinya, Siwanant Thaiwitcharoen, Supranee Kaewpirom, and Ubolluk Rattanasak. 2013. "Controlling Ettringite Formation in FBC Fly Ash Geopolymer Concrete." Cement and Concrete Composites, 41, 24-28. doi: 10.1016/j.cemconcomp.2013.04.009.

Davidovits, J. 1989. “Geopolymers and Geopolymeric Materials.” Journal of Thermal Analysis 35(2), 429-441. doi: 10.1007/BF01904446.

DeMerlis, C. C., and D. R. Schoneker. 2003. "Review of the Oral Toxicity of Polyvinyl Alcohol (PVA)." Food and Chemical Toxicology, 41(3), 319-326.

Derringer, George, and Ronald Suich. 1980. "Simultaneous Optimization of Several Response Variables." Journal of Quality Technology, 12(4), 214219. doi: $10.1080 / 00224065.1980 .11980968$.

Diaz-Loya, E. Ivan, Erez N. Allouche, and Saiprasad Vaidya. 2011. "Mechanical Properties of Fly-Ash-Based Geopolymer Concrete." ACI Materials Journal, 108(3), 300-306. doi: 10.14359/51682495.

Durak, Ugur, Serhan Ilkentapar, Okan Karahan, Burak Uzal, and Cengiz Duran Atiş. 2021. "A New Parameter Influencing the Reaction Kinetics and Properties of Fly Ash Based Geopolymers: A Pre-Rest Period before Heat Curing." Journal of Building Engineering 35, 102023. doi: 10.1016/j.jobe.2020.102023. 


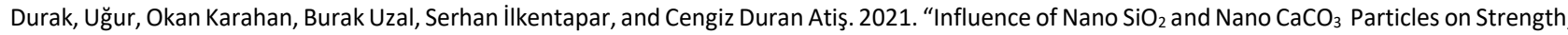
Workability, and Microstructural Properties of Fly Ash-based Geopolymer." Structural Concrete 22(S1), E352-E367. doi: $10.1002 /$ suco.201900479.

Elyamany, Hafez E., Abd Elmoaty M. Abd Elmoaty, and Ahmed M. Elshaboury. 2018. "Magnesium Sulfate Resistance of Geopolymer Mortar." Construction and Building Materials, 184, 111-127. doi: 10.1016/j.conbuildmat.2018.06.212

Global Carbon Atlas. 2020. Retrieved (http://www.globalcarbonatlas.org/en/CO2-emissions).

Jones, J. I. 1973. Polyvinyl Alcohol. Properties and Applications. UK: Jhon Wiley, Chichester.

Kaur, Mandeep, Jaspal Singh, and Manpreet Kaur. 2018. "Microstructure and Strength Development of Fly Ash-Based Geopolymer Mortar: Role of Nano-Metakaolin." Construction and Building Materials, 190, 672-679. doi: 10.1016/j.conbuildmat.2018.09.157.

Kaya, Mehmet, Mucteba Uysal, Kemalettin Yilmaz, and Cengiz Duran Atis. 2018. "Behaviour of Geopolymer Mortars after Exposure to Elevated Temperatures." Medziagotyra 24(4), 428-436. doi: 10.5755/j01.ms.24.4.18829.

Kaya, Mehmet, Mücteba Uysal, Kemalettin Yilmaz, Okan Karahan, and C. Duran Atis. 2020. "Mechanical Properties of Class C and F Fly Ash Geopolymer Mortars." Gradjevinar, 72(4), 297-309. doi: 10.14256/JCE.2421.2018.

Keke, Sun, Peng Xiaoqin, Wang Shuping, and Zeng Lu. 2019. "Design Method for the Mix Proportion of Geopolymer Concrete Based on the Paste Thickness of Coated Aggregate." Journal of Cleaner Production, 232, 508-517. doi: 10.1016/j.jclepro.2019.05.254.

Ling, Yifeng, Kejin Wang, Wengui Li, Guyu Shi, and Ping Lu. 2019. "Effect of Slag on the Mechanical Properties and Bond Strength of Fly Ash-Based Engineered Geopolymer Composites." Composites Part B: Engineering, 164, 106898. doi: 10.1016/j.compositesb.2019.01.092.

Ling, Yifeng, Peng Zhang, Juan Wang, and Yuanzhao Chen. 2019. "Effect of PVA Fiber on Mechanical Properties of Cementitious Composite with and without Nano-SiO2." Construction and Building Materials, 229, 117068. doi: 10.1016/j.conbuildmat.2019.117068.

Montgomery, D. C. 2017. Design and Analysis of Experiments: Response Surface Method and Designs. UK: John Wiley and Sons Ltd.

Muraleedharan, Manjusha, and Yashida Nadir. 2021. "Factors Affecting the Mechanical Properties and Microstructure of Geopolymers from Red Mud and Granite Waste Powder: A Review." Ceramics International 47(10, Part A), 13257-79. doi: https://doi.org/10.1016/j.ceramint.2021.02.009.

Neupane, Kamal. 2018. "High-Strength Geopolymer Concrete- Properties, Advantages and Challenges." Advances in Materials, 7(2), 15-25. doi: 10.11648/j.am.20180702.11.

Niyilola Braima, Maryam, Ambrose Nworah Anozie, and Oludare Johnson Odejobi. 2016. Utilization of Response Surface Methodology (RSM) in the Optimization of Crude Oil Refinery Process, New Port-Harcourt Refinery, Nigeria. Vol. 3.

Okoye, F. N., J. Durgaprasad, and N. B. Singh. 2015. "Fly Ash/Kaolin Based Geopolymer Green Concretes and Their Mechanical Properties." Data in Brief, 5, 739-734. doi: 10.1016/j.dib.2015.10.029.

Rahmiati, Tia, Khairun Azizi Azizli, Zakaria Man, Lukman Ismail, and Muhd Fadhil Nuruddin. 2014. "The Effect of KOH Concentration on Setting Time and Compressive Strength of Fly Ash-Based Geopolymer." in Applied Mechanics and Materials, Vol. 625, 94-97.

Ravitheja, A., and N. L. N. Kiran Kumar. 2019. "A Study on the Effect of Nano Clay and GGBS on the Strength Properties of Fly Ash Based Geopolymers." in Materials Today: Proceedings, 19, 273-276.

Rifaai, Yasser, Ammar Yahia, Ahmed Mostafa, Salima Aggoun, and El Hadj Kadri. 2019. "Rheology of Fly Ash-Based Geopolymer: Effect of NaOH Concentration." Construction and Building Materials, 223, 583-594. doi: 10.1016/j.conbuildmat.2019.07.028.

Ritchie, Hannah, Esteban Ortiz-Ospina, Diana Beltekian, Edouard Mathieu, Joe Hassel, Bobbie Macdonald, Charlie Giattino, Cameron Appel, and Max Roser. 2021. "Our World in Data." Retrieved (https://ourworldindata.org/grapher/annual-coemissions-by-region).

Ryu, Gum Sung, Young Bok Lee, Kyung Taek Koh, and Young Soo Chung. 2013. "The Mechanical Properties of Fly Ash-Based Geopolymer Concrete with Alkaline Activators." Construction and Building Materials, 47, 409-418. doi: 10.1016/j.conbuildmat.2013.05.069.

Şahin, Murat, Mahdi Mahyar, and Sinan T. Erdoğan. 2016. "Mutual Activation of Blast Furnace Slag and a High-Calcium Fly Ash Rich in Free Lime and Sulfates." Construction and Building Materials, 126, 466-475. doi: 10.1016/j.conbuildmat.2016.09.064.

Sarıdemir, Mustafa, and Serhat Çelikten. 2020. "Investigation of Fire and Chemical Effects on the Properties of Alkali-Activated Lightweight Concretes Produced with Basaltic Pumice Aggregate." Construction and Building Materials, 260, 119969. doi: 10.1016/j.conbuildmat.2020.119969.

Shi, Zhenguo, Caijun Shi, Shu Wan, and Zuhua Zhang. 2018. "Effects of Alkali Dosage and Silicate Modulus on Alkali-Silica Reaction in Alkali-Activated Slag Mortars." Cement and Concrete Research, 111, 104-115. doi: 10.1016/j.cemconres.2018.06.005

Sofi, M., J. S. J. van Deventer, P. A. Mendis, and G. C. Lukey. 2007. "Engineering Properties of Inorganic Polymer Concretes (IPCS)." Cement and Concrete Research, 37(2), 251-257. doi: 10.1016/j.cemconres.2006.10.008.

Tanyildizi, Harun, and Yavuz Yonar. 2016. "Mechanical Properties of Geopolymer Concrete Containing Polyvinyl Alcohol Fiber Exposed to High Temperature." Construction and Building Materials, 126, 381-387. doi: 10.1016/j.conbuildmat.2016.09.001.

TS EN 1015-11. 2019. "Methods of Test for Mortar for Masonry-Part 11: Determination of Flexural and Compressive Strength of Hardened Mortar."

TS EN 1015-3. 1999. "Methods of Test for Mortar for Masonry- Part 3: Determination of Consistence of Fresh Mortar (by Flow Table)."

TS EN 1015-11. 2019. "Methods of Test for Mortar for Masonry-Part 11: Determination of Flexural and Compressive Strength of Hardened Mortar."

Wang, Yaguang, Xiaoming Liu, Wei Zhang, Zepeng Li, Yuliang Zhang, Yong Li, and Yongyu Ren. 2020. "Effects of Si/Al Ratio on the Efflorescence and Properties of Fly Ash Based Geopolymer." Journal of Cleaner Production, 242, 118436. doi: 10.1016/j.jclepro.2019.118852. 
Xu, Fang, Xin Deng, Chao Peng, Jing Zhu, and Jianping Chen. 2017. "Mix Design and Flexural Toughness of PVA Fiber Reinforced Fly Ash-Geopolymer Composites." Construction and Building Materials, 150, 179-189. doi: 10.1016/j.conbuildmat.2017.05.172.

Xu, Shilang, Muhammad Akbar Malik, Zhang Qi, Bo Tao Huang, Qinghua Li, and Manas Sarkar. 2018. "Influence of the PVA Fibers and SiO2 NPs on the Structural Properties of Fly Ash Based Sustainable Geopolymer." Construction and Building Materials, 164, $238-245$. doi: 10.1016/j.conbuildmat.2017.12.227.

Zhang, Z. H., H. J. Zhu, C. H. Zhou, and H. Wang. 2016. “Geopolymer from Kaolin in China: an overview.” Applied Clay Science, 119, 31-41. 